S. LEBIEDIEWA

\title{
SYSTEMY MODALNEGO RACHUNKU NAZW
}

\section{(Streszczenie)}

W drugiej części omówione są dwa systemy modalnego rachunku nazw $O_{\mu}^{\prime}$ i $O_{\mu}^{\prime \prime}$.

$\mathbb{W}$ języku tych systemów występują zmienne będące funktorami nazwotwórczymi od argumentów nazwowych $\mu$ (może być) i $\lambda$ (musi być). Pierwszy $z$ tych terminów jest terminem pierwotnym, drugi jest zdefiniowany $w$ sposób następujący:

$$
x \lambda S \equiv x \varepsilon x \wedge \sim x \mu S^{\prime}
$$

Oprócz aksjomatu ontologii A0, aksjomatami systemu $O_{\mu}^{\prime}$ są wyrażenia

A1. $\quad x \mu S \equiv \sum_{\nu}(y \mu x) \wedge \prod_{y, z}(y \mu x \wedge z \mu x \rightarrow y \mu z) \wedge \prod_{y}(y \mu x \rightarrow y \mu S)$

A2. $x \varepsilon S \rightarrow x \mu S$

A3. $x \mu S+P \rightarrow x \mu S \vee x \mu P$

A4. $\quad x|\mu y \wedge \rightarrow| y \mid \rightarrow y \mu x$

A5. $x \mu S \wedge S a P \rightarrow x \mu P$

Regułami systemu $O_{\mu}^{\prime}$ są reguły ontologii.

Aksjomatami systemu $O_{\mu}^{\prime \prime}$ są wyrażenia A0-A4. Regułami systemu $O_{\mid 1}^{\prime \prime}$ są reguly ontologii oraz

REGULA I. Jeżeli tezą ontologii jest wyrażenie $x \Sigma \omega_{1} \rightarrow x \varepsilon \omega_{2}$, to tezą systemu $O_{: \alpha}^{\prime \prime}$ jest wyrażenie $x \mu \omega_{1} \rightarrow x \mu \omega_{2}\left(\omega_{1} \mathrm{i} \omega_{2}\right.$ są wyrażeniami nazwowymi).

System $O_{\mu}^{\prime \prime}$ jest ostro zawarty w systemie $O_{\mu}^{\prime}$, który z kolei jest ostro zawarty w systemie $O_{L}$. Systemy $O_{\mu}^{\prime \prime}$ i $O_{s 5}$ krzyżują się. W pracy dowodzi się, że aksjomat A5 nie jest tezą systemu $O_{\mu}^{\prime \prime}$.

Zdaniem autorki spośród systemów $O_{L}, O_{S 5}, O_{\mu}^{\prime}$ i $O_{\mu}^{\prime \prime}$ system $O_{\mu}^{\prime \prime}$ jest najbliższy intuicjom związanym $z$ potocznym używaniem terminów modalnych. 